\title{
Stability Analysis of Competing Insect Species for a Single Resource
}

\author{
Sizah Mwalusepo, ${ }^{1,2}$ Henri E. Z. Tonnang, ${ }^{1}$ Estomih S. Massawe, ${ }^{2}$ \\ Tino Johansson, ${ }^{3}$ and Bruno Pierre Le Ru ${ }^{1,4,5}$ \\ ${ }^{1}$ African Insect Science for Food and Health (icipe), P.O. Box 30772-00100, Nairobi, Kenya \\ ${ }^{2}$ Department of Mathematics, University of Dar es Salaam, P.O. Box 35062, Dar es Salaam, Tanzania \\ ${ }^{3}$ CHIESA Project, African Insect Science for Food and Health (icipe), P.O. Box 30772-00100, Nairobi, Kenya \\ ${ }^{4}$ Unité de Recherche IRD 072, Laboratoire Evolution, Génomes et Spéciation, UPR 9034, 22 CNRS, 91198 Gif/Yvette, France \\ ${ }^{5}$ Université Paris-Sud 11, 91405 Orsay, France
}

Correspondence should be addressed to Sizah Mwalusepo; mwalusepo@yahoo.com

Received 22 February 2014; Accepted 12 June 2014; Published 6 July 2014

Academic Editor: Carlos Conca

Copyright (C) 2014 Sizah Mwalusepo et al. This is an open access article distributed under the Creative Commons Attribution License, which permits unrestricted use, distribution, and reproduction in any medium, provided the original work is properly cited.

\begin{abstract}
The models explore the effects of resource and temperature on competition between insect species. A system of differential equations is proposed and analysed qualitatively using stability theory. A local study of the models is performed around axial, planar, and interior equilibrium points to successively estimate the effect of (i) one species interacting with a resource, (ii) two competing species for a single resource, and (iii) three competing species for a single resource. The local stability analysis of the equilibrium is discussed using Routh-Hurwitz criteria. Numerical simulation of the models is performed to investigate the sensitivity of certain key parameters. The models are used to predict population dynamics in the selected cases studied. The results show that when a single species interacts with a resource, the species will be able to establish and sustain a stable population. However, in competing situation, it is observed that the combinations of three parameters (half-saturation, growth rate, and mortality rate) determine which species wins for any given resource. Moreover, our results indicate that each species is the superior competitor for the resource for the range of temperature for which it has the lowest equilibrium resource.
\end{abstract}

\section{Introduction}

During the past decades the theory of competition has played an increasingly important role in both development of general ecological theory and the interpretation of field data [1]. Competition is one of the primary biotic factors that shape patterns of distribution, abundance, and diversity in ecological communities [2]. The prominent status of competition in modern ecology is undoubtedly linked to views of pioneers in ecology. They strongly advocate the central role of competitive interactions between species [35]. The term "species" in the present study represents insect. Plant-feeding insects have become focal organisms for studies on population dynamics and community diversity because competition is deeply ingrained in their activities. It became accepted as a factor organizing insect assemblages, despite the fact that empirical evidence supporting competition was mostly derived from plant, vertebrate, and marine systems $[6,7]$. In this circumstance the importance of interspecific competition is a highly controversial and unresolved issue for community ecology in general and for phytophagous insect in particular. Many theoretical studies of interspecific competition have dealt with the dependence of competition on the resource utilization abilities of each species [8-11]. The models used in these studies usually belong to two groups; the first group uses the classical theory of ecological competition between two or more species [12-14] that is attributed to Lotka [15] and Volterra [16]. These models are often "phenomenological" because the competition parameters are not independently derived values that can allow direct prediction of coexistence [17]. The second group employs resource-based theory in ecological competition; it 
considers the dynamic of the resource explicitly as well as the population dynamics of the competing species $[8,9,17$, 18]. The simplest form of resource-based competition occurs in laboratory apparatus, called a chemostat or continuous culture $[3,11]$. In comparison with the classical models, the resource-based models may be less general and more difficult to analyse $[8,19,20]$. However, the resource-based models are often more predictive because the parameters can be measured on species alone [21]. Although competition among species is often cited as a major determinant of natural distributional patterns, there have been few studies in which knowledge of the mechanism of competition is used to predict these patterns [17]. The many biotic and abiotic factors that influence competition and possible interactions among them make such prediction difficult.

Climate, especially temperature, has a strong and direct effect on insect development, reproduction, and survival $[22,23]$. This abiotic factor can be used to define ecological suitability of insect species and can thus dictate composition of pest communities in different agroecological regions. It affects life histories, insect distributions, interactions with host-plants, and their antagonists [22, 23]. However, this important parameter (temperature) has not much been incorporated in the theoretical studies relating resource and insect competition. Therefore, the objective of the present work is to determine and analyse the stability of the equilibrium points of insect species competing for a single resource while accounting for temperature through qualitatively analysis. We analyse the system as a combination of three submodels: (i) a single species with a single resource, (ii) two species competing for one resource, and (iii) three species competing for one resource.

\section{Model Formulation}

To formulate the model, the following assumptions are taken into consideration.

(i) The growth of the insect species is limited by a single resource.

(ii) All insect species require the same resource to survive and reproduce.

(iii) The resource availability depends on the rate of resource supply.

(iv) No biological control measure is applied; that is, no parasitoid is applied.

(v) The dynamic is assumed to follow "Monod's" type function.

(vi) All values of the competition coefficient are nonnegative.

(vii) The growth rate is a function of both resource and temperature.

Taking into account the above considerations, then we have the schematic flow charts (Figure 1).

From the flow charts, three systems of ordinary differential equations governing the growth and the dependence of the species to the resource were deduced.
2.1. Case 1: One Species and One Resource Model. Consider

$$
\begin{aligned}
\frac{d N_{1}}{d t} & =\left(r_{1} \exp \left(\frac{-1}{2}\left(\frac{T-T_{1}}{w}\right)^{2}\right) \frac{R}{k_{1}+R}-m_{1}\right) N_{1}, \\
\frac{d R}{d t} & =\beta(S-R)-\alpha_{1} r_{1} \exp \left(\frac{-1}{2}\left(\frac{T-T_{1}}{w}\right)^{2}\right) \frac{R}{k_{1}+R} N_{1} .
\end{aligned}
$$

2.2. Case 2: Two Species and One Resource Model. Consider

$$
\begin{aligned}
\frac{d N_{1}}{d t}= & \left(r_{1} \exp \left(\frac{-1}{2}\left(\frac{T-T_{1}}{w}\right)^{2}\right) \frac{R}{k_{1}+R}-m_{1}\right) N_{1}, \\
\frac{d N_{2}}{d t}= & \left(r_{2} \exp \left(\frac{-1}{2}\left(\frac{T-T_{2}}{w}\right)^{2}\right) \frac{R}{k_{2}+R}-m_{2}\right) N_{2}, \\
\frac{d R}{d t}= & \beta(S-R)-\alpha_{1} r_{1} \exp \left(\frac{-1}{2}\left(\frac{T-T_{1}}{w}\right)^{2}\right) \frac{R}{k_{1}+R} N_{1} \\
& -\alpha_{2} r_{2} \exp \left(\frac{-1}{2}\left(\frac{T-T_{2}}{w}\right)^{2}\right) \frac{R}{k_{2}+R} N_{2} .
\end{aligned}
$$

2.3. Case 3: Three Species and One Resource Model. Consider

$$
\begin{aligned}
\frac{d N_{1}}{d t}= & \left(r_{1} \exp \left(\frac{-1}{2}\left(\frac{T-T_{1}}{w}\right)^{2}\right) \frac{R}{k_{1}+R}-m_{1}\right) N_{1}, \\
\frac{d N_{2}}{d t}= & \left(r_{2} \exp \left(\frac{-1}{2}\left(\frac{T-T_{2}}{w}\right)^{2}\right) \frac{R}{k_{2}+R}-m_{2}\right) N_{2}, \\
\frac{d N_{3}}{d t}= & \left(r_{3} \exp \left(\frac{-1}{2}\left(\frac{T-T_{3}}{w}\right)^{2}\right) \frac{R}{k_{3}+R}-m_{3}\right) N_{3}, \\
\frac{d R}{d t}= & \beta(S-R)-\alpha_{1} r_{1} \exp \left(\frac{-1}{2}\left(\frac{T-T_{1}}{w}\right)^{2}\right) \frac{R}{k_{1}+R} N_{1} \\
& -\alpha_{2} r_{2} \exp \left(\frac{-1}{2}\left(\frac{T-T_{2}}{w}\right)^{2}\right) \frac{R}{k_{2}+R} N_{2} \\
& -\alpha_{3} r_{3} \exp \left(\frac{-1}{2}\left(\frac{T-T_{3}}{w}\right)^{2}\right) \frac{R}{k_{3}+R} N_{3} .
\end{aligned}
$$

Let $a_{i}=r_{i} \exp \left((-1 / 2)\left(\left(T-T_{i}\right) / w\right)^{2}\right), i=1,2,3$, in these systems.

The Michaelis-Menten equation $R /\left(k_{i}+R\right)$ is employed to describe the relationship between cellular metabolism and resource. For every large value of the resource, this equation gives approximately a value of 1 . For a resource equal to $k_{i}$, it gives approximately a value of $1 / 2$, which justifies why $k_{i}$ is referred to as the half-saturation constant. To be biologically relevant, the following conditions must be satisfied: $R(0)>$ 0 and $N_{i}(0)>0$. The variables and parameters used in the models are described in Abbreviation Section. 


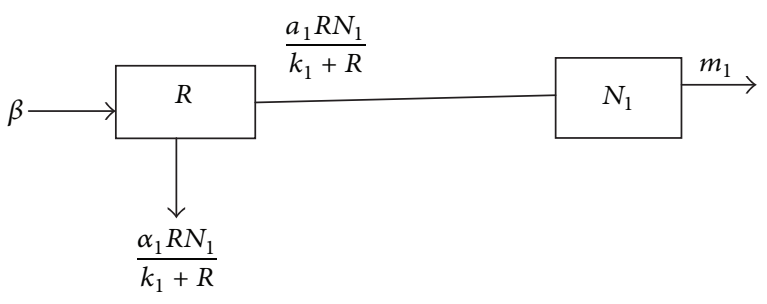

(a)

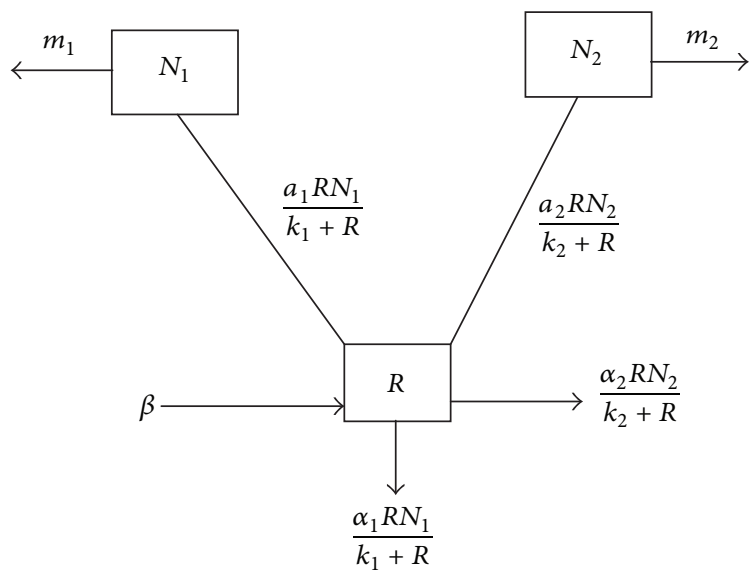

(b)

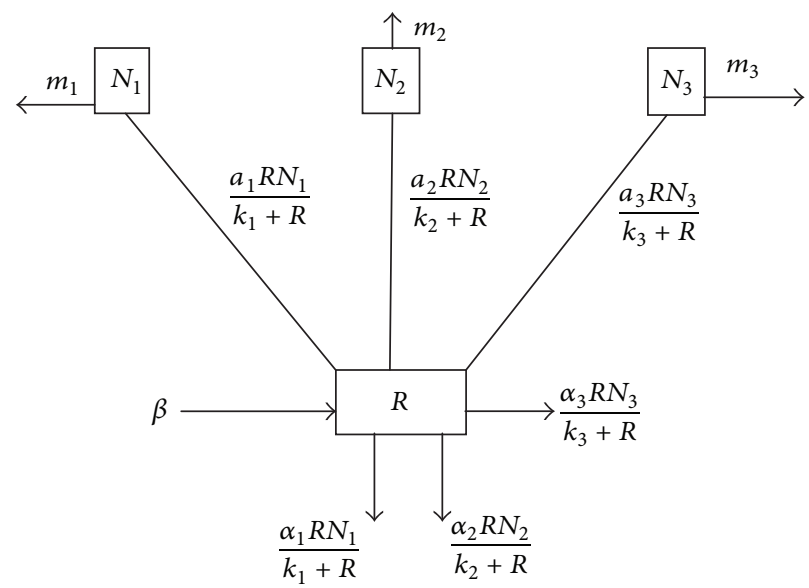

(c)

FIGURE 1: Flow charts summarizing the conceptual framework of the formulated models; the boxes represent state variables, which describe the state or condition of the system components. The arrows illustrate relationships among state variables as the movement of ecological interactions; (a) shows one species and one resource interactions, (b) represents two species competing for one resource, and (c) illustrates three species competing for one resource.

\section{Models Analysis}

The mathematical models equations (1)-(3) are analysed qualitatively. An elaborative analysis of the equilibrium is performed and conditions for existence of the proposed systems are provided. The stability analysis of the equilibrium is studied by computing the variational matrices for each equilibrium point. However, the local stability is established through Jacobian matrix of the systems using the RouthHurwitz criteria. For linearized systems, the Jacobian matrix is given by

$$
\mathbf{J}=\left[\begin{array}{ccccc}
\frac{\partial f_{1}}{\partial N_{1}} & \cdots & \cdots & \cdots & \frac{\partial f_{1}}{\partial N_{n}} \\
\vdots & \ddots & & \vdots \\
\vdots & & \ddots & & \vdots \\
\vdots & & & \ddots & \vdots \\
\frac{\partial f_{k}}{\partial N_{1}} & \cdots & \cdots & \cdots & \frac{\partial f_{k}}{\partial N_{n}}
\end{array}\right]
$$

This is associated with the characteristic equation:

$$
\operatorname{det}(J-\lambda I)=0 \Longrightarrow \lambda^{n}+b_{1} \lambda^{n-1}+b_{2} \lambda^{n-2}+\cdots+b_{n}=0
$$

In general, the characteristic equation is a polynomial expression with degree $n$ equal to the number of species competing, $\lambda$ is the eigenvalues of the linearized system, and $\mathbf{I}$ is the identity matrix.

Theorem 1 (Routh-Hurwitz criteria). Given the polynomial $P(\lambda)=\lambda^{n}+b_{1} \lambda^{n-1}+b_{2} \lambda^{n-2}+\cdots+b_{n}$, where the coefficients $b_{i}$ are real constants, $i=1, \ldots, n$, define the $n$ Hurwitz matrices using the coefficients $b_{i}$ of the characteristic polynomial. Then, all of the roots of the polynomial $P(\lambda)$ are negative or have negative real parts if and only if the determinants of all Hurwitz matrices are positive. For polynomial of degree $n=2,3$ and 4, the Hurwitz criteria are summarized as follows: $\operatorname{Re}\left(\lambda_{i}\right)<0$ if $n=2: b_{1}>0, b_{2}>0 ; n=3: b_{1}>0, b_{3}>0, b_{1} b_{2}>b_{3} ; n=4$ : $b_{1}>0, b_{3}>0, b_{4}>0$, and $b_{1} b_{2} b_{3}>b_{3}^{2}+b_{1}^{2} b_{4}$. 
Theorem 2. For an $n \times n$ matrix $\mathbf{A}$ the determinant is given by the explicit formula $\operatorname{det}(A)=\sum_{\sigma \in S_{n}} \operatorname{sgn}(\sigma) \prod_{i=1}^{n} A_{i}, \sigma_{i}$, where $s_{n}$ is the permutation group, $\operatorname{sgn}(\sigma)$ is the signum function of permutation in the permutation group, which returns +1 and -1 for even and odd permutation, respectively, and $\sigma_{i}$ represents the value in ith position after the reordering.

\subsection{Models Implementation and Population Size Predictions.} The calculations are carried out with computer program written in $R$. In the program, model equations are solved using the 4th order Runge-Kutta algorithm with step size of 0.01 . Once the models equations are solved, graphs are generated displaying predictions of future species population size at fixed initial number of the resource. For a random selection of species, initial population size, the models are used to estimate the values of species at a given time interval; that may be day, week, or month depending on the species life cycle.

\subsection{Qualitative Analysis of the Developed Models}

3.2.1. One Species and One Resource. The model for this case has at most two equilibrium points, namely, axial equilibrium point $E_{1}\left(0, R^{*}\right)$ and interior equilibrium point $E_{2}\left(N_{1}^{*}, R^{*}\right)$. The asterisk on $N^{*}$ and $R^{*}$ indicates that this is a nonzero equilibrium value of $N$ and $R$, respectively. These equilibrium points are obtained when $d N_{i} / d t=0, i=1,2,3$, and $d R / d t=0$. The local stability of each equilibrium point of model system (1) is ascertained by the following theorem.

Theorem 3. (a) By using the Routh-Hurwitz criterion, $E_{1}(0, S)$ is locally asymptotically stable if

$$
\begin{aligned}
& 0<\frac{\beta k_{1}+\beta S-S a_{1}+S m_{1}+m_{1} k_{1}}{k_{1}+S}, \\
& \text { when } \beta+m_{1}>\frac{a_{1} S}{k_{1}+S}, \\
& 0<-\frac{\beta\left(S\left(a_{1}-m_{1}\right)-m_{1} k_{1}\right)}{k_{1}+S} .
\end{aligned}
$$

(b) The interior point $E_{2}\left(\beta\left(S\left(a_{1}-m_{1}\right)-m_{1} k_{1}\right) / \alpha_{1} m_{1}\left(a_{1}-\right.\right.$ $\left.\left.m_{1}\right), m_{1} k_{1} /\left(a_{1}-m_{1}\right)\right)$ is locally asymptotically stable if

$$
\begin{aligned}
& 0<\frac{\left(a_{1}-m_{1}\right)\left(S a_{1}-S m_{1}-m_{1} k_{1}\right) \beta}{a_{1} k_{1}}, \\
& 0<\frac{\left(S a_{1}^{2}-2 a_{1} S m_{1}+S m_{1}^{2}+m_{1}^{2} k_{1}\right) \beta}{a_{1} k_{1} m_{1}} .
\end{aligned}
$$

3.2.2. Two Species One Resource. Model (2) has three equilibrium points, which are

$$
\begin{gathered}
E_{1}(0,0, S), \quad E_{2}\left(\frac{\beta\left(S\left(a_{1}-m_{1}\right)-m_{1} k_{1}\right)}{\alpha_{1} m_{1}\left(a_{1}-m_{1}\right)}, 0, \frac{m_{1} k_{1}}{a_{1}-m_{1}}\right), \\
E_{3}\left(0, \frac{\beta\left(S\left(a_{2}-m_{2}\right)-m_{2} k_{2}\right)}{\alpha_{2} m_{2}\left(a_{2}-m_{2}\right)}, \frac{m_{2} k_{2}}{a_{2}-m_{2}}\right) .
\end{gathered}
$$

Theorem 4. Through Routh-Hurwitz criteria, the equilibrium points $E_{1}\left(0,0, R^{*}\right), E_{2}\left(N_{1}^{*}, 0, R_{1}^{*}\right)$, and $E_{3}\left(0, N_{2}^{*}, R_{2}^{*}\right)$ will be locally asymptotically stable if the following conditions hold: for the polynomial degree $n=3$, the equilibrium points can be determined without explicitly solving the characteristic polynomial $\lambda^{3}+\psi_{1} \lambda^{2}+\psi_{2} \lambda+\psi_{3}=0$. Then $\operatorname{Re}\left(\lambda_{i}\right)<0$ if $\psi_{1}>0, \psi_{3}>0, \psi_{1} \psi_{2}-\psi_{3}>0$; otherwise, the equilibrium points will be unstable.

3.2.3. Three Species One Resource. For this case, the system of ordinary differential equations has four equilibrium points:

$$
\begin{gathered}
E_{1}(0,0,0, S), \\
E_{2}\left(\frac{\beta\left(S\left(a_{1}-m_{1}\right)-m_{1} k_{1}\right)}{\alpha_{1} m_{1}\left(a_{1}-m_{1}\right)}, 0,0, \frac{m_{1} k_{1}}{a_{1}-m_{1}}\right), \\
E_{3}\left(0, \frac{\beta\left(S\left(a_{2}-m_{2}\right)-m_{2} k_{2}\right)}{\alpha_{2} m_{2}\left(a_{2}-m_{2}\right)}, 0, \frac{m_{2} k_{2}}{a_{2}-m_{2}}\right), \\
E_{4}\left(0,0, \frac{\beta\left(S\left(a_{3}-m_{3}\right)-m_{3} k_{3}\right)}{\alpha_{3} m_{3}\left(a_{3}-m_{3}\right)}, \frac{m_{3} k_{3}}{a_{3}-m_{3}}\right) .
\end{gathered}
$$

Theorem 5. The equilibrium point $E_{1}(0,0,0, S)$ is locally asymptotically stable if (i) $A>0$, (ii) $C>0$, (iii) $D>0$, and (iv) $A B C>C^{2}+A^{2} D$; otherwise, it will be unstable.

Proof. The determinant of the Jacobian matrix at $E_{1}(0,0,0, S)$ is given by

$$
\operatorname{det}\left[\begin{array}{cccc}
\frac{a_{1} S}{k_{1}+S}-m_{1}-\lambda & 0 & 0 & 0 \\
0 & \frac{a_{2} S}{k_{2}+S}-m_{2}-\lambda & 0 & 0 \\
0 & 0 & \frac{a_{3} S}{k_{3}+S}-m_{3}-\lambda & 0 \\
-\frac{\alpha_{1} a_{1} S}{k_{1}+S} & -\frac{\alpha_{2} a_{2} S}{k_{2}+S} & -\frac{\alpha_{3} a_{3} S}{k_{3}+S} & -\beta-\lambda
\end{array}\right]
$$

$=0$.

Let

$$
\begin{gathered}
L_{1}=\frac{a_{1} S}{k_{1}+S}-m_{1}, \quad L_{2}=\frac{a_{2} S}{k_{2}+S}-m_{2}, \\
L_{3}=\frac{a_{3} S}{k_{3}+S}-m_{3}, \quad L_{4}=\frac{-a_{1} \alpha_{1} S}{k_{1}+S}, \\
L_{5}=\frac{-a_{2} \alpha_{2} S}{k_{2}+S}, \quad L_{6}=\frac{-a_{3} \alpha_{3} S}{k_{3}+S} .
\end{gathered}
$$

Then the characteristic equation of the matrix is calculated as

$$
\lambda^{4}+A \lambda^{3}+B \lambda^{2}+C \lambda+D=0,
$$

where

$$
\begin{aligned}
& A=\beta-L_{1}-L_{2}-L_{3}, \\
& B=L_{1} L_{2}+L_{1} L_{3}+L_{2} L_{3}-L_{1} \beta-L_{2} \beta-L_{3} \beta, \\
& C=L_{1} L_{2} \beta+L_{1} L_{3} \beta+L_{2} L_{3} \beta-L_{1} L_{2} L_{3}, \\
& D=-L_{1} L_{2} L_{3} \beta .
\end{aligned}
$$


Applying the Routh-Hurwitz criterion applied on a 4-by-4 matrix, $E_{1}(0,0,0, S)$ will be locally asymptotically stable if $A>0, C>0, D>0$, and $A B C>C^{2}+A^{2} D$ and unstable otherwise.

Theorem 6. The planar equilibrium points, $E_{2}\left(N_{1}^{*}, 0,0, R_{1}^{*}\right)$, $E_{3}\left(0, N_{2}^{*}, 0, R_{2}^{*}\right)$, and $E_{4}\left(0,0, N_{3}^{*}, R_{3}^{*}\right)$ are locally asymptotically stable if (i) $\Omega_{1}>0$, (ii) $\Omega_{3}>0$, (iii) $\Omega_{4}>0$, and (iv) $\Omega_{1} \Omega_{2} \Omega_{3}>\Omega_{3}^{2}+\Omega_{1}^{2} \Omega_{4}$.

Proof. The Jacobian matrix at $E_{2}\left(N_{1}^{*}, 0,0, R_{1}^{*}\right)$ is given by

$$
\mathbf{J}_{E_{2}}=\left[\begin{array}{cccc}
A_{11} & 0 & 0 & A_{41} \\
0 & A_{22} & 0 & 0 \\
0 & 0 & A_{33} & 0 \\
A_{14} & A_{24} & A_{34} & A_{44}
\end{array}\right],
$$

where

$$
\begin{aligned}
& A_{11}=\frac{a_{1} R_{1}^{*}}{k_{1}+R_{1}^{*}}-m_{1}, \\
& A_{41}=N_{1}^{*}\left(\frac{a_{1}}{k_{1}+R_{1}^{*}}-\frac{a_{1} R_{1}^{*}}{\left(k_{1}+R_{1}^{*}\right)^{2}}\right), \\
& A_{22}=\frac{a_{2} R_{1}^{*}}{k_{2}+R_{1}^{*}}-m_{2}, \quad A_{33}=\frac{a_{3} R_{1}^{*}}{k_{3}+R_{1}^{*}}-m_{3}, \\
& A_{14}=\frac{-\alpha_{1} a_{1} R_{1}^{*}}{k_{1}+R_{1}^{*}}, \quad A_{24}=\frac{-\alpha_{2} a_{2} R_{1}^{*}}{k_{2}+R_{1}^{*}}, \\
& A_{34}=\frac{-\alpha_{3} a_{3} R_{1}^{*}}{k_{3}+R_{1}^{*}}, \quad A_{44}=-\frac{\alpha_{1} a_{1} N_{1}^{*}}{k_{1}+R_{1}^{*}}-\beta+\frac{\alpha_{1} a_{1} N_{1}^{*} R_{1}^{*}}{\left(k_{1}+R_{1}^{*}\right)^{2}} .
\end{aligned}
$$

The determinant of $\mathbf{J}_{E_{2}}$ is given by

$$
\operatorname{det}\left[\begin{array}{cccc}
A_{11}-\lambda & 0 & 0 & A_{41} \\
0 & A_{22}-\lambda & 0 & 0 \\
0 & 0 & A_{33}-\lambda & 0 \\
A_{14} & A_{24} & A_{34} & A_{44}-\lambda
\end{array}\right]=0 .
$$

The characteristic equation is

$$
\lambda^{4}+Z_{1} \lambda^{3}+Z_{2} \lambda^{2}+Z_{3} \lambda+Z_{4}=0
$$

where

$$
\begin{aligned}
Z_{1}= & -\left(A_{11}+A_{22}+A_{33}+A_{44}\right), \\
Z_{2}= & A_{11} A_{22}+A_{22} A_{33}+A_{11} A_{33}+A_{11} A_{44} \\
& +A_{22} A_{44}+A_{33} A_{44}-A_{41} A_{14}, \\
Z_{3}= & A_{41} A_{14} A_{22}+A_{41} A_{14} A_{33}-A_{11} A_{33} A_{22} \\
& -A_{11} A_{33} A_{44}-A_{22} A_{33} A_{44}, \\
Z_{4}= & A_{11} A_{22} A_{33} A_{44}-A_{41} A_{14} A_{22} A_{33} .
\end{aligned}
$$

Applying the Routh-Hurwitz criterion, the planar equilibrium point $E_{2}$ will be locally asymptotically stable if (i) $Z_{1}>$ 0 , (ii) $Z_{3}>0$, (iii) $Z_{4}>0$, and (iv) $Z_{1} Z_{2} Z_{3}>Z_{3}^{2}+Z_{1}^{2} Z_{4}$.
TABLE 1: Parameters used in simulations.

\begin{tabular}{lccc}
\hline Parameters & Species one & Species two & Species three \\
\hline$r_{i}$ & 0.1 & 0.17 & 0.2 \\
$m_{i}$ & 0.02 & 0.02 & 0.02 \\
$\beta$ & 0.01 & 0.01 & 0.01 \\
$S$ & 70 & 70 & 70 \\
$k_{i}$ & 0.02 & 0.1 & 0.7 \\
$\alpha_{i}$ & 3 & 0.5 & 0.4 \\
$w$ & 7 & 7 & 7 \\
$T_{i}$ & 22 & 20 & 23 \\
\hline
\end{tabular}

Similarly, for $E_{3}\left(0, N_{2}^{*}, 0, R_{2}^{*}\right)$ and $E_{4}\left(0,0, N_{3}^{*}, R_{3}^{*}\right)$, again through the Routh-Hurwitz criteria, we have the following: from the polynomial $\lambda^{4}+n_{1} \lambda^{3}+n_{2} \lambda^{2}+n_{3} \lambda+n_{4}=0$, with $\operatorname{Re}\left(\lambda_{i}\right)<0$ if $n_{1}>0, n_{3}>0, n_{4}>0$, and $n_{1} n_{2} n_{3}>n_{3}^{2}+n_{1}^{2} n_{4}$ the system will be conditionally stable.

3.3. Resource Response to Temperature. It is useful to determine the quantitative and qualitative behaviour of planar equilibrium in response to temperature, since the quantity of resource can highly vary within any particular region of qualitatively similar parameters space. In this effect, let us consider the resource as a function of temperature with the following expression:

$$
R_{i}^{*}=\frac{g_{i}}{r_{i} \exp \left((-1 / 2)\left(\left(T-T_{i}\right) / w\right)^{2}\right)-m_{i}},
$$

where $g_{i}=m_{i} k_{i}, k_{i}, T_{i}, m_{i}, r_{i}, w, T$ are constants.

We determine the response of $R_{i}^{*}$ to temperature using the derivate $d R_{i}^{*} / d T$.

The derivative of the equilibrium of the temperature dependent resource function with respect to temperature is a dampened exponential function given by

$$
\begin{aligned}
\frac{d R_{i}^{*}}{d T}= & g_{i}\left(\frac{T}{w^{2}}-\frac{T_{i}}{w^{2}}\right) \times r_{i} \exp \left(-\frac{1}{2}\left(\frac{T-T_{i}}{w}\right)^{2}\right) \\
& \times\left(\left[r_{i} \exp \left(\frac{-1}{2}\left(\frac{T-T_{i}}{w}\right)^{2}-m_{i}\right)\right]^{2}\right)^{-1} .
\end{aligned}
$$

This generates a rather simple relationship governing the directional response of equilibrium resource to temperature variation. For numerical simulation, the parameters are chosen to give the behaviour of the isoclines for the species and the resource. This is done using three different sets of parameters (unequal growth rate, equal growth rate, and equal consumption rates). Due to the lack of parameters values in the literature and from the field study we assumed the following values in Table 1 to simulate the model.

\section{Results}

This section presents the results of the numerical simulations that were carried out to investigate the dynamical behaviour of the formulated models. In order to verify the theoretical 
predications of the models, the numerical simulations are carried out using fixed values of the model parameters of the models. These parameters values are chosen for simulation purposes only. However, these parameters may be biologically feasible. Numerical simulations for three species are done singly at five different temperatures $\left(10^{\circ} \mathrm{C}, 15^{\circ} \mathrm{C}, 20^{\circ} \mathrm{C}\right.$, $25^{\circ} \mathrm{C}$, and $30^{\circ} \mathrm{C}$ ) and the results are represented in Figures 2 , $3,4,5,6,7,8$, and 9 .

At $10^{\circ} \mathrm{C}$ (Figure 2(a)), for a single species, the results show a slow increase in the curve of the species population size and a slow decrease in the resource quantity. At $15^{\circ} \mathrm{C}, 20^{\circ} \mathrm{C}$, $25^{\circ} \mathrm{C}$, and $30^{\circ} \mathrm{C}$, respectively, similar curves behaviour shape is obtained. It starts with a rapid increase of the population size of the species, followed by slow decreases and a rapid decrease of the resource. Figure 2(b) shows the relationship between the different initial population size (10,20, and 30) with the resource at $25^{\circ} \mathrm{C}$; it was observed that the more the initial population size of the species the resource quantity decrease faster.

For two species competing for a single resource (Figures $3-5)$, the results show that species one is a superior competitor at all temperatures tested when the initial population size of species one is greater than species two and within $20-30^{\circ} \mathrm{C}$ when both species started at the same initial population size. Species two is a superior competitor at all temperatures tested when the initial population size of species two is greater than species one and at $10^{\circ} \mathrm{C}$ when both species started at the same initial population size. No difference is observed between the two species at $15^{\circ} \mathrm{C}$ when the initial population size of the two species is identical.

In the case of three species competing for a single resource, the species with higher initial population size is the superior competitor at all temperatures. However, when all species have equal initial population size, species two grew faster than its two counterparts at lower temperatures (from $10^{\circ} \mathrm{C}$ to $15^{\circ} \mathrm{C}$ ). Between $20^{\circ} \mathrm{C}$ and $25^{\circ} \mathrm{C}$ species one is superior competitor. With the same growth rates, the species with the lower mortality is the superior competitor when all species have equal initial population size. It is observed that one species is the superior competitor at $10^{\circ} \mathrm{C}$ to $15^{\circ} \mathrm{C}$ and with increase in temperature $\left(T \geq 20^{\circ} \mathrm{C}\right)$ another species became superior when all species have equal consumption rates.

Figure 10 represents a combination of temperature and resource for which each species has no net population growth for a given mortality rate. Herein, the zero net growth isoclines represent equilibrium boundaries of individual species based on their requirements in resource availability. The curves show the amount of the resource that each species needs at equilibrium to have a reproductive rate that can balance its mortality rate. In general, within the unshaded region, the population size of the species will increase, while it would decrease in the shaded region.

\section{Discussion}

We have conducted a qualitative analysis of the effects of resource and temperature on competition between insect species. For this purpose, temperature dependent system of differential equations was formulated. Both qualitative and numerical analyses of the models were considered. In respect to each model, the axial, planar, and interior equilibrium points were obtained and their stabilities were investigated. Conditions on the parameters that insure the stability and instability of the boundary equilibrium points were presented. For a single species interacting with the resource, the local stability analyses revealed that the species could maintain a stable population when growing alone under all conditions used in the analysis. It was illustrated that as the population size of the species grows, the resource depletes to the level of equilibrium of the resource availability where the population size of the species stops growing. Numerical simulation also revealed that the dynamical outcomes of the interactions are very sensitive to the model parameter values and to the initial population size of the species. In axial equilibrium point, it was observed that if the value of the equilibrium of the resource availability is too large than the supply point of the resource, the population of the species cannot persist. In one hand, this is due to the fact that the resource availability directly depends on the rate of resource supply. On the other hand, if the supply of the resource is sufficiently large, the species can establish a stable population and equally control the resource to the equilibrium of the resource availability.

Generally, the obtained results highlight an essential assumption of the resource competition theory, which suggested that when several species compete for the same resource, the species with the lowest requirement for the resource is the superior competitor at equilibrium [24]. This species competitively displaces all its counterparts, independent of the initial size of the population for other competing species. This means that at the equilibrium points, in a habitat with a single limiting resource, the best competitor is the species that has the lowest equilibrium resource value $\left(R_{i}^{*}\right)$. It implies that a given species $i$ is able to continue growing as long as the resource is greater than the lowest equilibrium resource value $\left(R>R_{i}^{*}\right)$. Reciprocally, species $i$ can go to local extinction if the resource is less than the lowest equilibrium resource $\left(R<R_{i}^{*}\right)$. For these values of $R$, the resource-dependent growth rates of the species is less than their mortality rates, and all species will experience negative exponential decline towards the equilibrium point. These results are in agreement with Tilman findings reported by Tilman [8].

From the formulated models, it was observed that the relationships between the available resource and resulting population size are nonlinear. This makes the analysis of the developed mathematical equations in varying temperature difficult. We therefore opted to conduct the analysis at fixed temperatures and then generalize by intervals [25-28]. The study of insects' physiology has demonstrated that different species have different temperature optimum that affects their competitive ability for resource exploitation [10]. To predict the outcome of competition between insect species within a range of temperatures, we superimpose the zero net growth isoclines of the species and results show that one species has an equilibrium resource significantly lower than its counterparts. 




(a)



(b)

FIGURE 2: Behavior of the isoclines for one species and the resource at different temperatures; (a) shows the behavior of population size and the resource at temperatures $10^{\circ} \mathrm{C}, 15^{\circ} \mathrm{C}, 20^{\circ} \mathrm{C}, 25^{\circ} \mathrm{C}$, and $30^{\circ} \mathrm{C}$, respectively; (b) shows the behavior of population size and resource at different initial population size at temperature $25^{\circ} \mathrm{C}$.

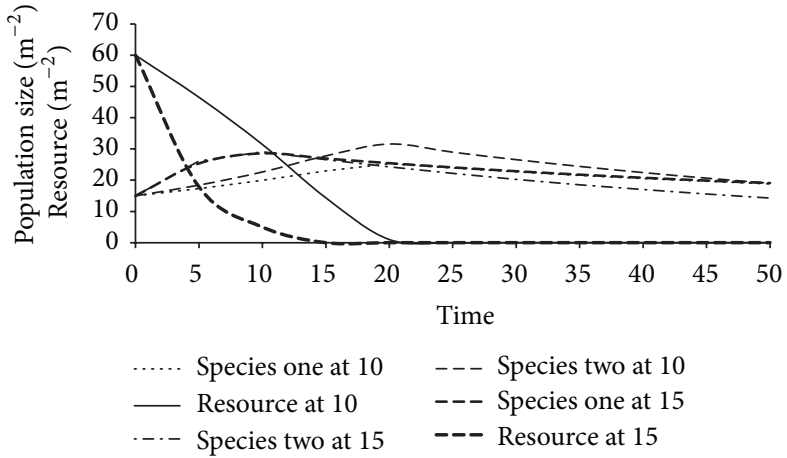

(a)

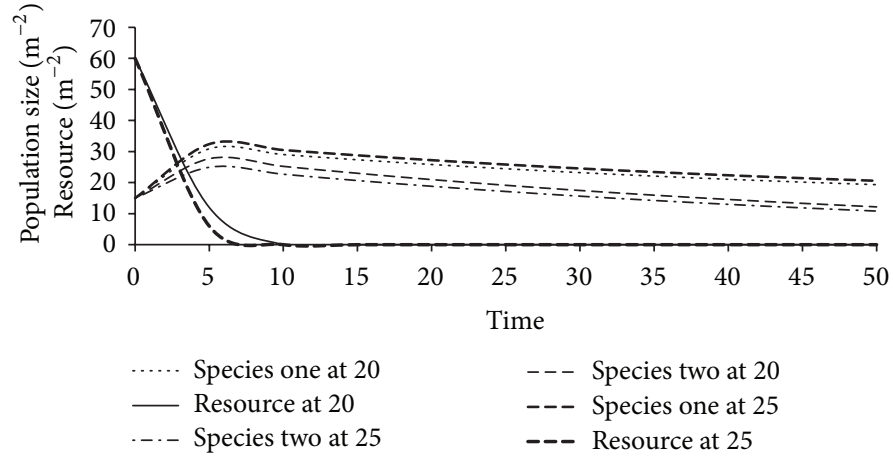

(b)

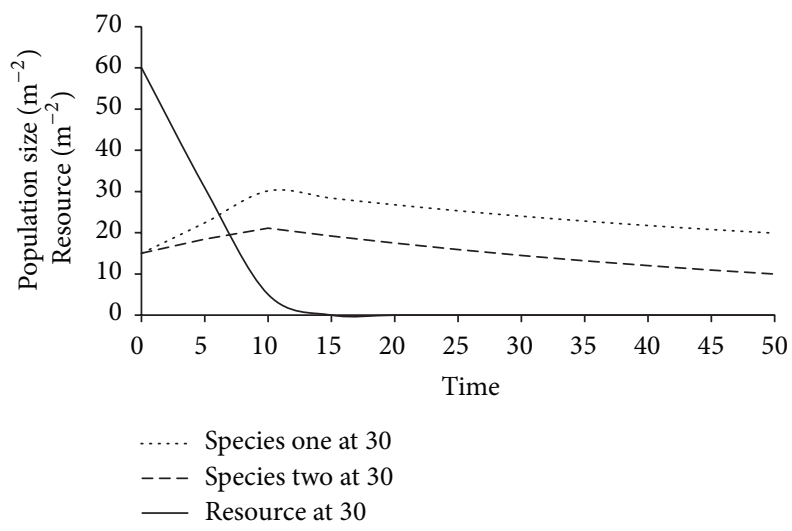

(c)

FIGURE 3: Behavior of the isoclines for two species competing for a single resource when both species initial population size are the same; curves (a)-(c) show the behavior of population size for each species and resource at temperatures: (a) $10^{\circ} \mathrm{C}$ and $15^{\circ} \mathrm{C}$, (b) $20^{\circ} \mathrm{C}$ and $25^{\circ} \mathrm{C}$, and (c) and $30^{\circ} \mathrm{C}$, respectively. 


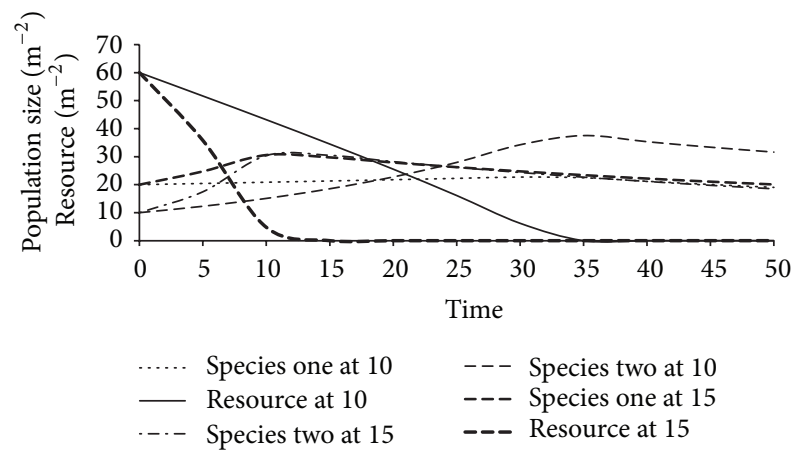

(a)


(b)

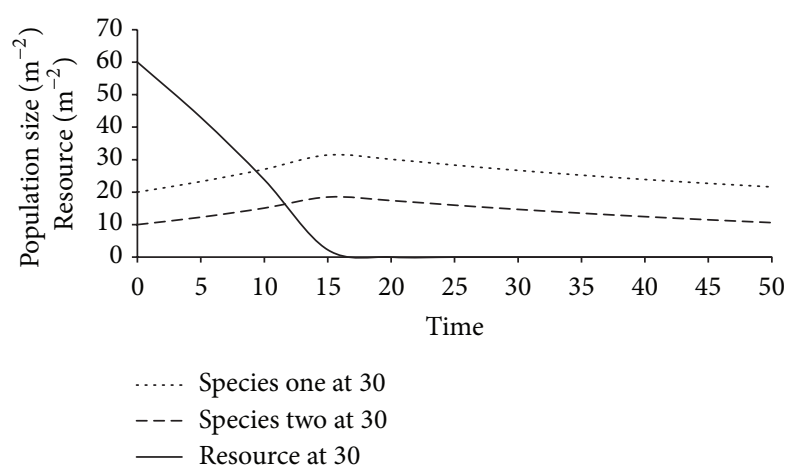

(c)

FIGURE 4: Behavior of the isoclines when the population size of species one is greater than species two; curves (a)-(c) show the behavior of population size for each species and the resource at temperatures: (a) $10^{\circ} \mathrm{C}$ and $15^{\circ} \mathrm{C}$, (b) $20^{\circ} \mathrm{C}$ and $25^{\circ} \mathrm{C}$, and (c) at $30^{\circ} \mathrm{C}$, respectively.

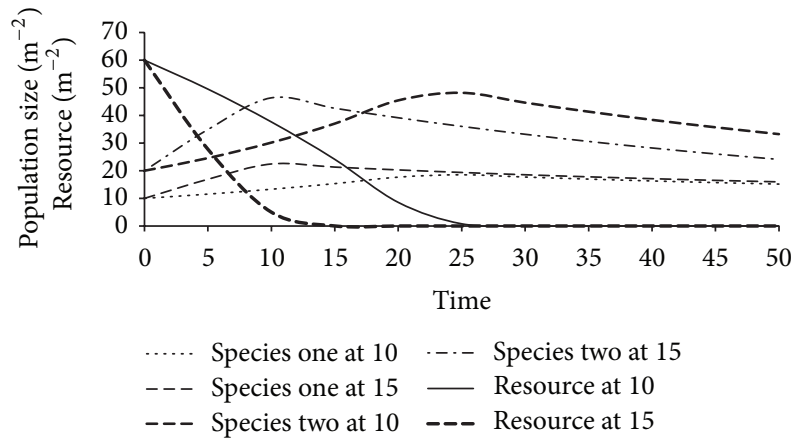

(a)



(b)

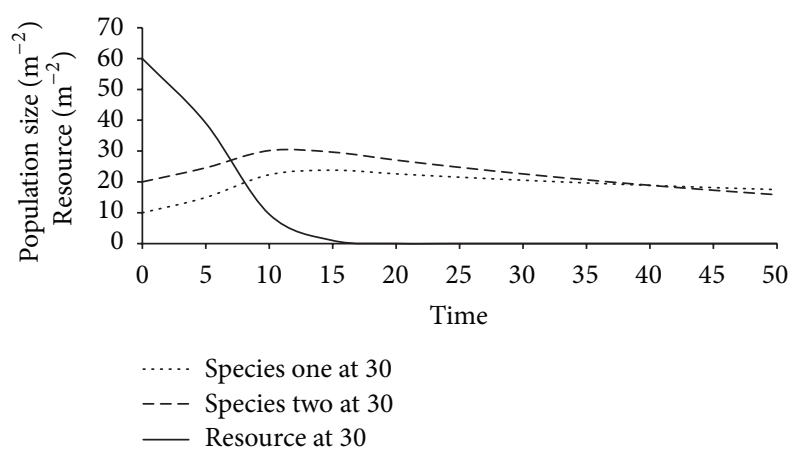

(c)

FIGURE 5: Behavior of the isoclines when the population size of species two is greater than species one; curves (a)-(c) show the behavior of population size for each species and the resource at temperatures: (a) $10^{\circ} \mathrm{C}$ and $15^{\circ} \mathrm{C}$, (b) $20^{\circ} \mathrm{C}$ and $25^{\circ} \mathrm{C}$, and (c) at $30^{\circ} \mathrm{C}$, respectively. 


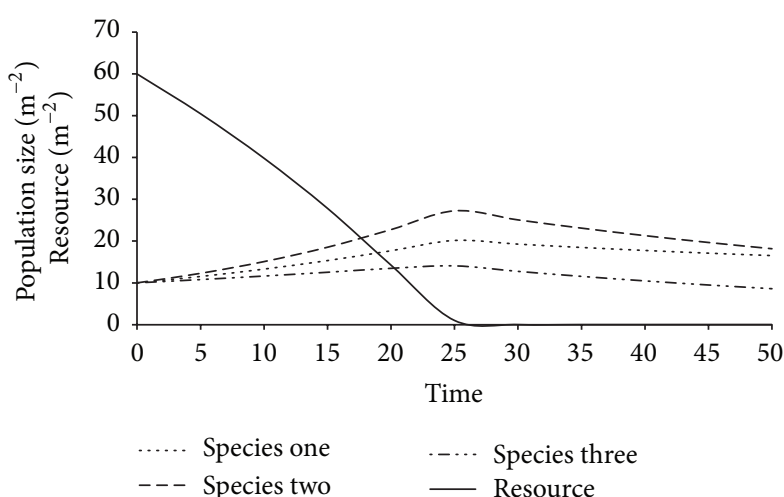

(a)



(c)



(b)

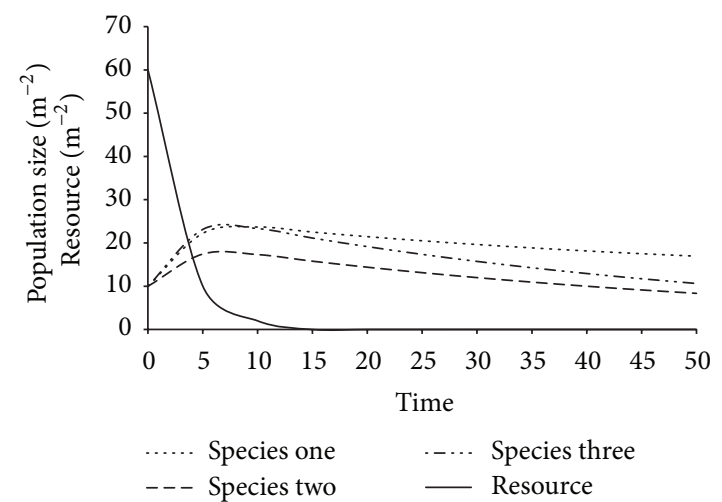

(d)

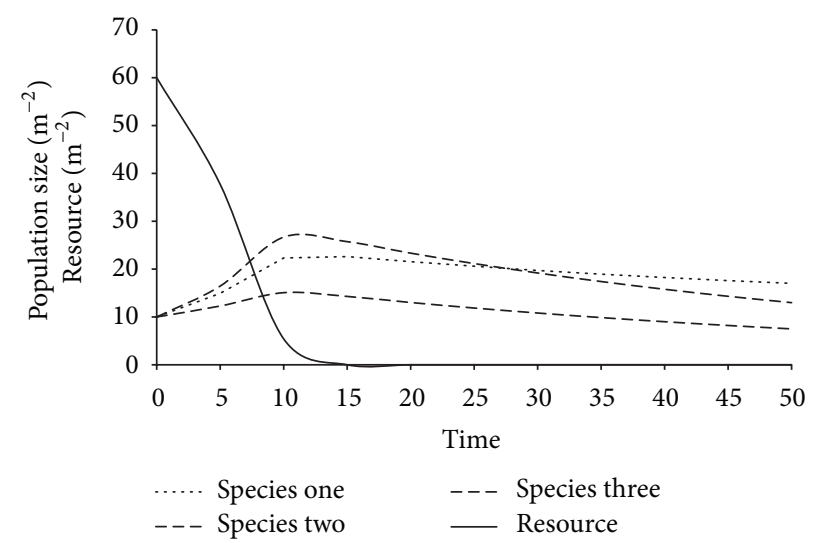

(e)

FIGURE 6: Behavior of the isoclines for three species competing for a single resource when both species initial population size are the same; curves (a)-(e) show the behavior of population size for each resource at temperatures $10^{\circ} \mathrm{C}, 15^{\circ} \mathrm{C}, 20^{\circ} \mathrm{C}, 25^{\circ} \mathrm{C}$, and $30^{\circ} \mathrm{C}$, respectively. The solid lines represent the resource; species one are represented with round dot lines, species two are represented with dash lines, and species three are represented with long dash dot lines and all species have different growth rate.

Furthermore, in a competing situation it is observed that three parameters, half-saturation constant, growth rate, and the mortality rate determine which species wins for any given resource. A species with a high affinity for the resource can still lose if it has low growth rate and a high death rate. This relationship is simple as it demonstrates that resourcebased models bring more understanding than the classical theory in ecology for species resource competition $[8,11]$. Moreover, the use of resource-based models emphasizes the role of resource in determining competitive interactions and the abilities of each species to acquire and use the limiting resource. Classical models of competition $[14,17]$ are useful tools for understanding insect population growth, whereas resource-based models create direct link between the species and the resource. These types of models are more predictive.

Further experimental or field investigation in this direction may be helpful to verify whether or not the process prescribed by the formulated models actually functions in a 


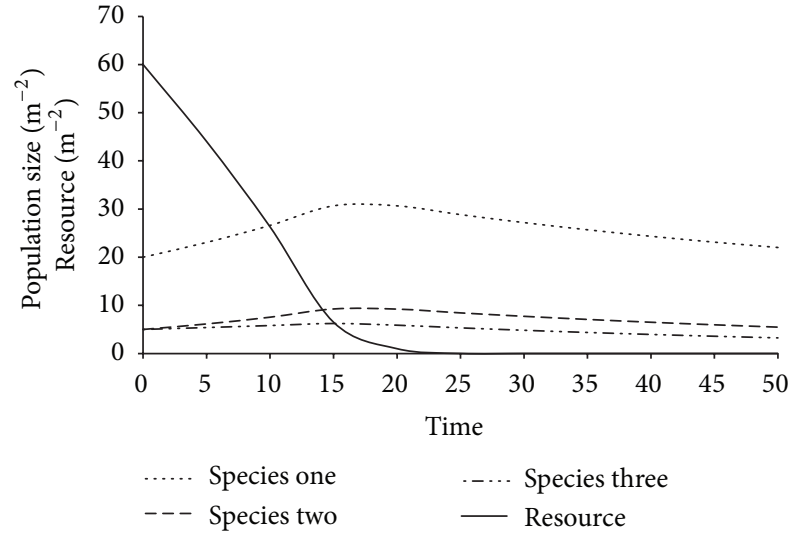

(a)

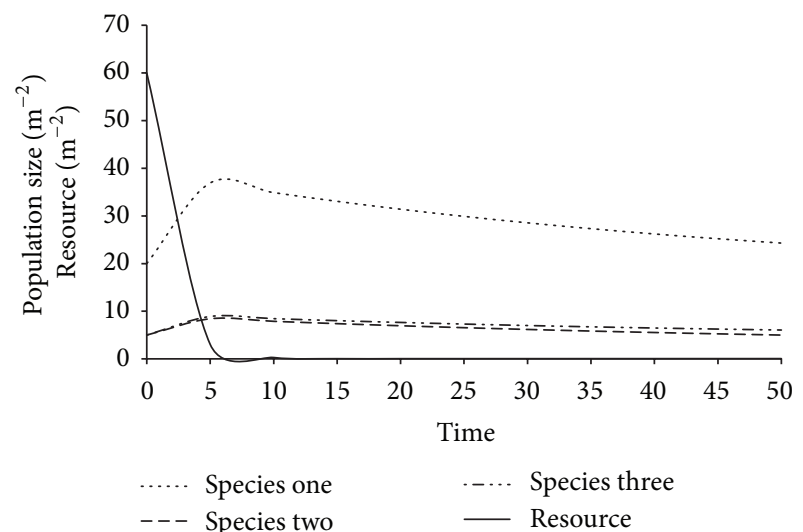

(c)

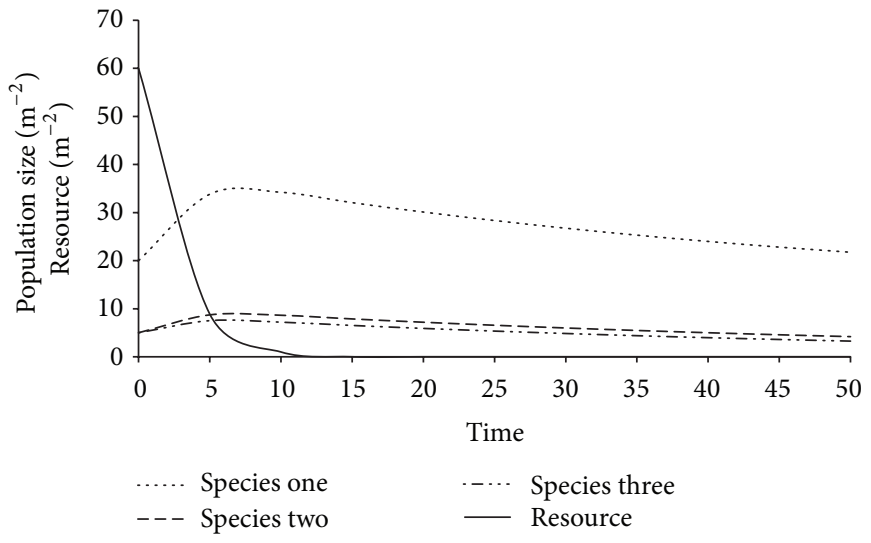

(b)

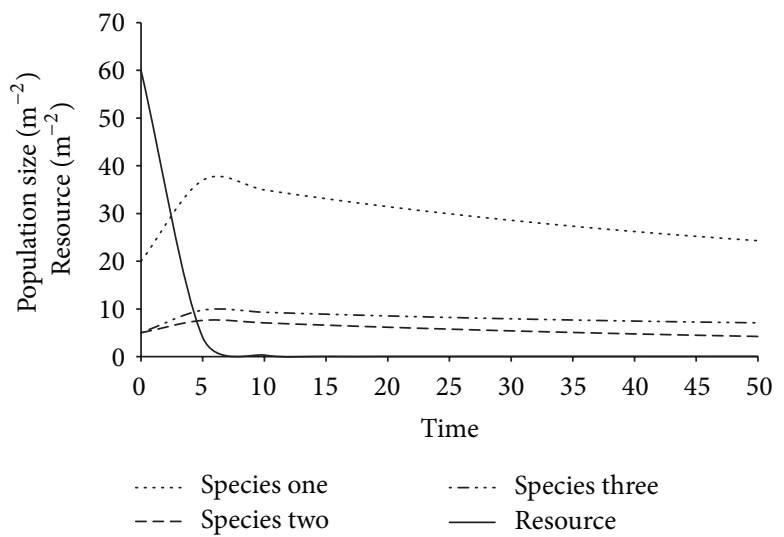

(d)

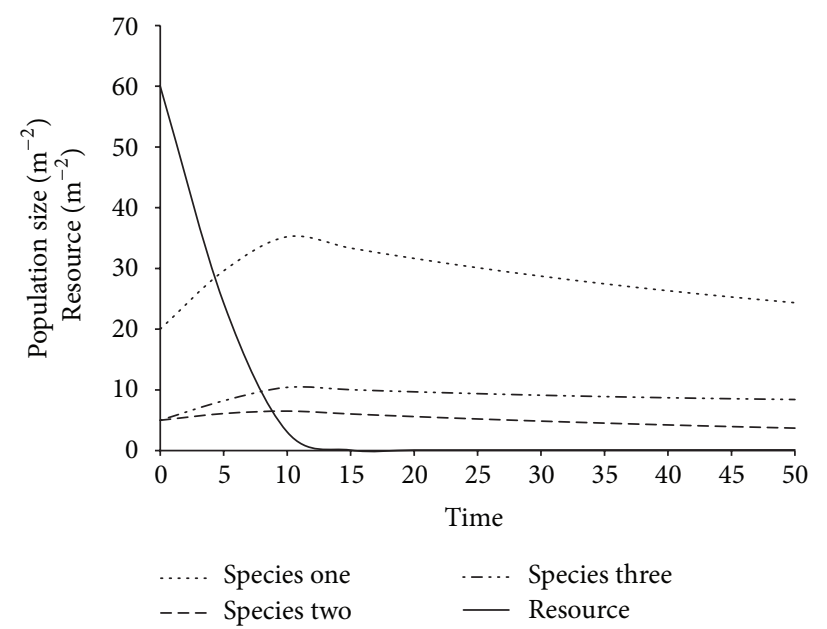

(e)

Figure 7: Behavior of the isoclines when initial, population size of species one is greater than species two and three; curves (a)-(e) show the behavior of population size for each species and resource at temperatures $10^{\circ} \mathrm{C}, 15^{\circ} \mathrm{C}, 20^{\circ} \mathrm{C}, 25^{\circ} \mathrm{C}$, and $30^{\circ} \mathrm{C}$, respectively.

similar manner under practical consideration. For example, we should verify the accuracy of our models on the maizelepidopteran stem borer pests system. In fact, maize is the most important staple food in most sub-Saharan Africa [29]. In spite of its importance, maize production is constrained by lepidopteran stem borer pests, the most damaging being the crambid Chilo partellus (Swinhoe) and the noctuid Busseola fusca (Fuller) and Sesamia calamistis Hampson [30]; more and in-depth research is needed on its predominant insect pests with different optimal temperatures to guide the formulation of appropriate adaptation strategies to the current climate change [31]. Therefore, our models can be a useful tool 


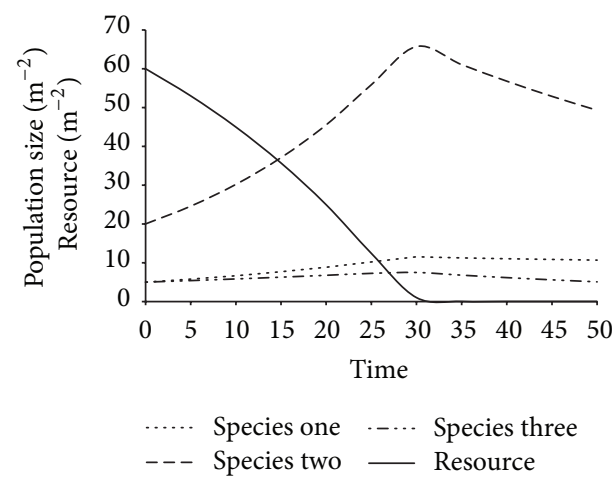

(a)

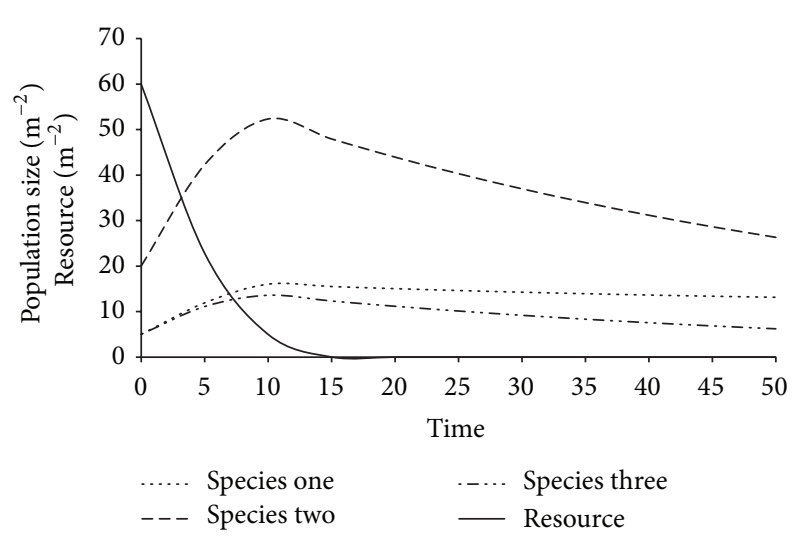

(c)

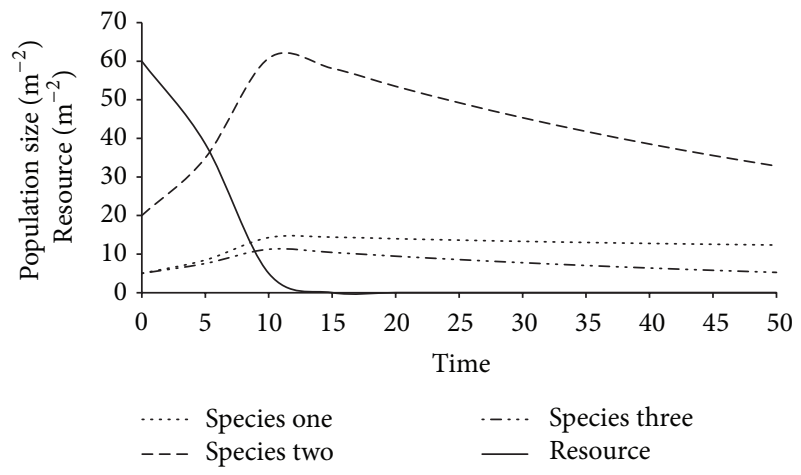

(b)



(d)

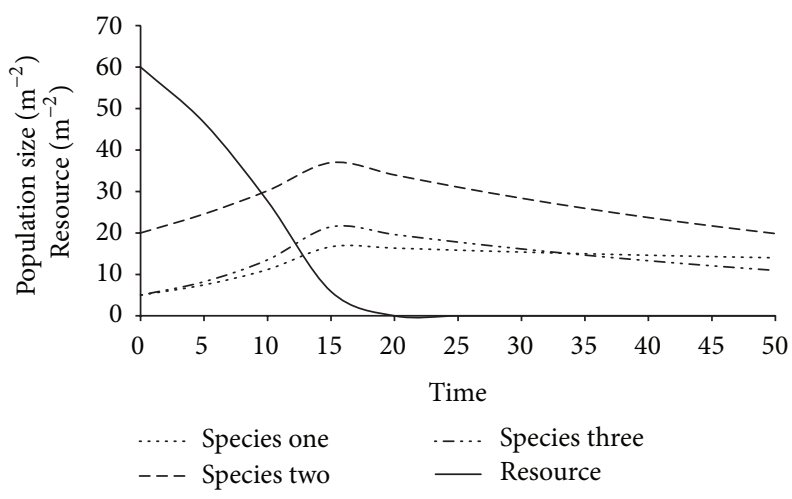

(e)

FIGURE 8: Behavior of the isoclines when the population size of species two is greater than that of species one and three; curves (a)-(e) show the behavior of population size for each species and resource at temperatures $10^{\circ} \mathrm{C}, 15^{\circ} \mathrm{C}, 20^{\circ} \mathrm{C}, 25^{\circ} \mathrm{C}$, and $30^{\circ} \mathrm{C}$, respectively.

to test how temperature can affect the competition between these insect pests, their future distribution, and incidence on maize production.

In conclusion, the present study qualitatively analysed a series of mathematical equations to demonstrate competition of insect species feeding on one resource. Therefore, it would be interesting to conduct further quantitative and qualitative studies for all kind of insect communities with different feeding behaviour (boring insects, chewing insects, and phloemfeeding insects) competing for one resource for possible improvement of integrated pest management strategies. Furthermore, many questions remain open including applying or improving the model and obtaining the results when the resource and insect species are in different stages (neonates and old instars larvae). Thus, purely observational methods may give an indication of whether competition is occurring, particularly if time-series data are used.

\section{Abbreviations}

$R(t)$ :

$N_{i}(t): \quad$ Population size of species $(i)$ at time $t$

$T: \quad$ The physical factor (temperature)

$T_{i}, i=1,2,3$ : The optimal temperature of species $(i)$ 


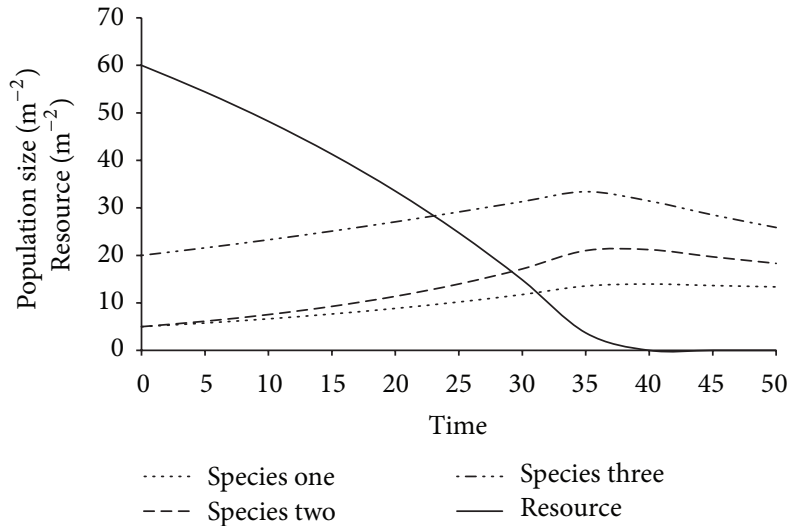

(a)

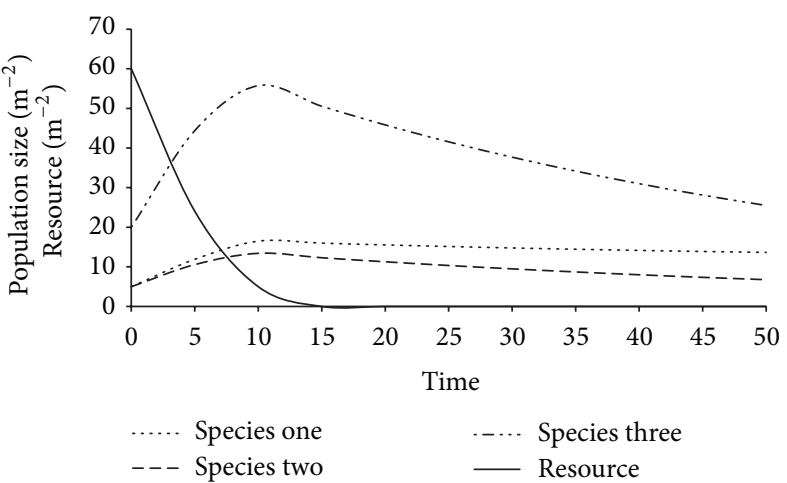

(c)

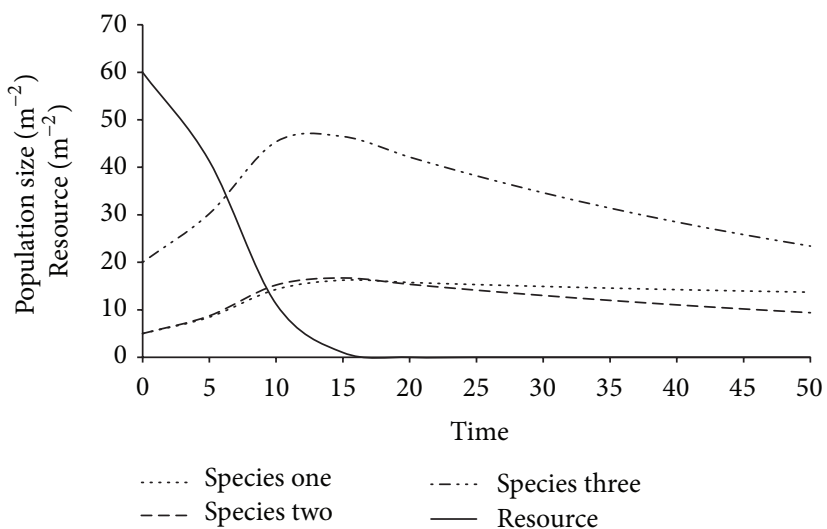

(b)

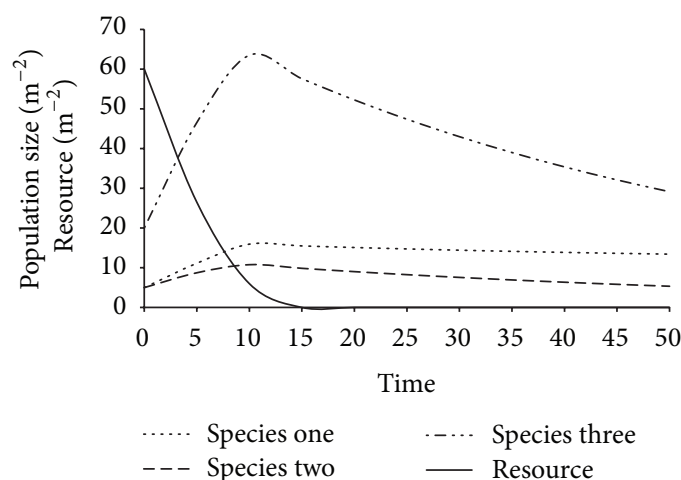

(d)



(e)

FIGURE 9: Behavior of the isoclines when the population size of species three is greater than species two and one; curves (a)-(e) show the behavior of population size for each species and the resource at temperatures $10^{\circ} \mathrm{C}, 15^{\circ} \mathrm{C}, 20^{\circ} \mathrm{C}, 25^{\circ} \mathrm{C}$, and $30^{\circ} \mathrm{C}$, respectively.

$r_{i}, i=1,2,3$ : Maximal gross productivity rate of species $i$ at temperature $T_{i}$

$a_{i}: \quad$ Population growth rate of species $(i)$

$\alpha_{i}$ : Consumption rate of the resource by species $(i)$

$m_{i}: \quad$ Mortality rate of species $(i)$

$k_{i}$ : $\quad$ The half-saturation constant of species $(i)$

$\beta$ : $\quad$ The flow or supply rate of the resource

S: $\quad$ The supply point

$w$ : The width environmental tolerance.

\section{Conflict of Interests}

The authors declare that there is no conflict of interests regarding the publication of this paper.

\section{Acknowledgments}

The authors are grateful to the entire members of the Noctuid Stem Borer Biodiversity (NSBB) team of the African Insect Science for Food and Health (icipe), the Institut de Recherche 


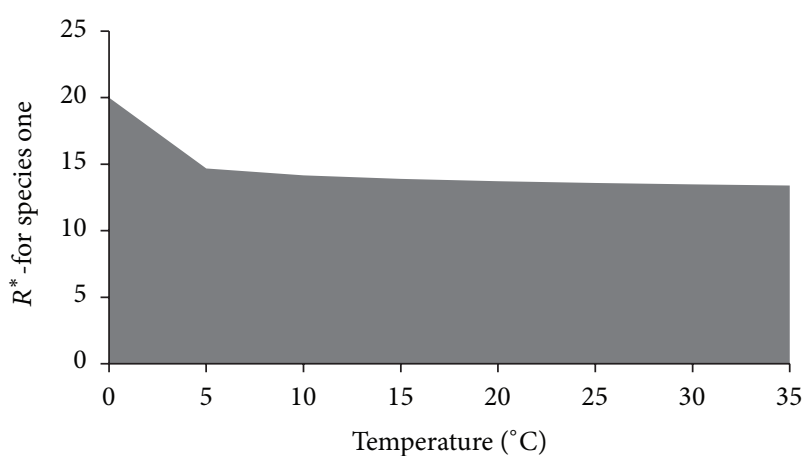

(a)

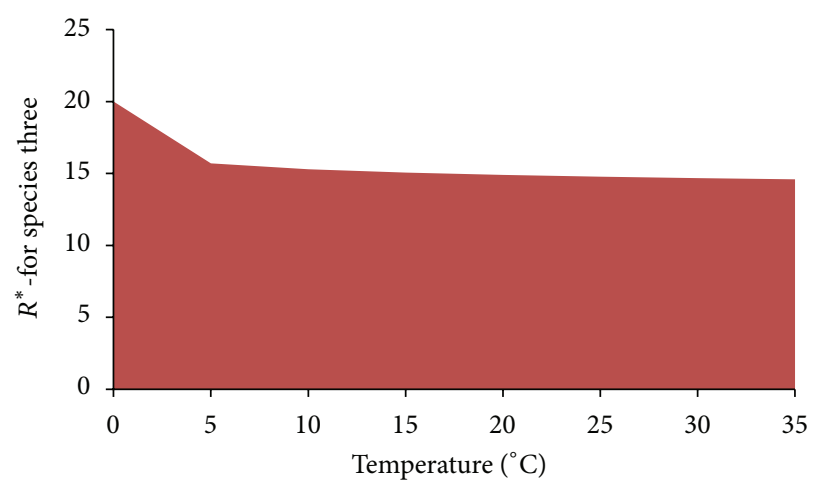

(c)

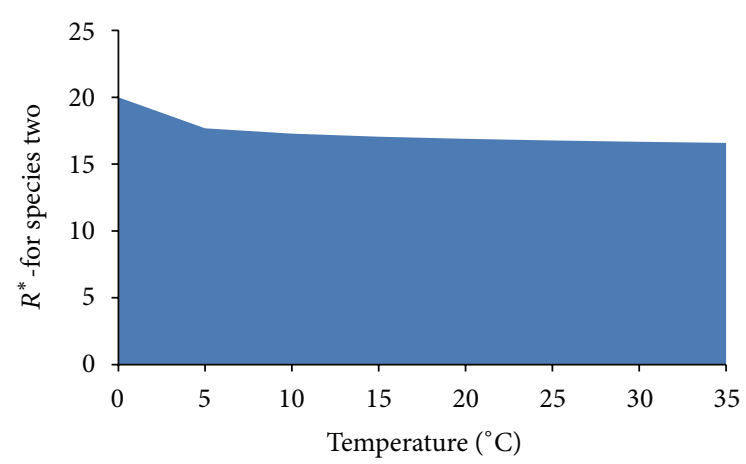

(b)

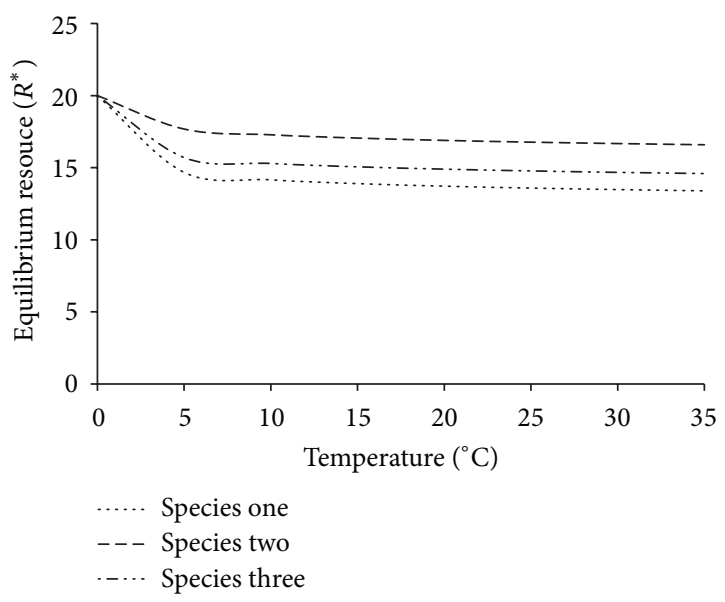

(d)

FIGURE 10: Temperature and equilibrium resource isoclines; curves (a)-(c) represent equilibrium boundaries of each species based on the requirements of equilibrium resource, within the unshaded region, the population size of the species will increase when it would decrease in shaded region, and (d) illustrated when three species are superimposed.

pour le Développment (IRD), and University of Dar es salaam, through the Department of Mathematics for their support. This research was conducted under the Climate Change Impacts on Ecosystem Services and Food Security in Eastern Africa (CHIESA) project. CHIESA is funded by the Ministry for Foreign Affairs of Finland.

\section{References}

[1] D. H. Robert, Predation, Apparent Competition, and the Structure of Prey Communities, Academic Press, New York, NY, USA, 1977.

[2] I. Kaplan and R. F. Denno, "Interspecific interactions in phytophagous insects revisited: a quantitative assessment of competition theory," Ecology Letters, vol. 10, no. 10, pp. 977-994, 2007.

[3] G. S. K. Wolkowicz and Z. Lu, "Global dynamics of a mathematical model of competition in the chemostat: general response functions and differential death rates," SIAM Journal on Applied Mathematics, vol. 52, no. 1, pp. 222-233, 1992.

[4] A. J. Lotka, "The growth of mixed populations: two species competing for a common food supply," Journal of Washington Academic of Science, vol. 22, no. 16, pp. 461-469, 1932.

[5] G. F. Gause, The Struggle for Existence, Williams and Wilkins, Baltimore, Md, USA, 1934.
[6] T. Jermy, "Is there competition between phytophagous insects?" Journal of Zoological Systematic and Evolutionary Research, vol. 23, no. 4, pp. 275-285, 1985.

[7] R. F. Denno, M. S. McClure, and J. R. Ott, "Interspecific interactions in phytophagous insects: competition reexamined and resurrected," Annual Review of Entomology, vol. 40, pp. 297331, 1995.

[8] D. Tilman, "Resource competition between planktonic algae: an experimental and theoretical approach," Ecology, vol. 58, no. 2, pp. $338-348,1977$.

[9] D. Tilman, "The importance of the mechanisms of interspecific competition," The American Naturalist, vol. 129, no. 5, pp. 769774, 1978.

[10] J. P. Grover, Resource Competition, Chapman \& Hall, London, $\mathrm{UK}, 1997$.

[11] I. P. Martines, H. V. Kojouharov, and J. P. Grover, "A chemostat model of resource competition and allelopathy," Applied Mathematics and Computation, vol. 215, no. 2, pp. 573-582, 2009.

[12] B. Liu and L. Zhang, "Dynamics of a two-species LotkaVolterra competition system in a polluted environment with pulse toxicant input," Applied Mathematics and Computation, vol. 214, no. 1, pp. 155-162, 2009.

[13] O. A. Ebraheen, A. D. Fordyce, and D. Niall, "A 3-species competition model for bio-control," Applied Mathematics and Computation, vol. 218, no. 18, pp. 9690-9698, 2012. 
[14] A. A. S. Zaghrout and F. M. Kandil, "Competition between three microbial populations for a single limiting resource in continuous culture," Applied Mathematics and Computation, vol. 92, no. 2-3, pp. 271-281, 1998.

[15] A. J. Lotka, Elementary of Physical Biology, Williams and Wilkins, Baltimore, Md, USA, 1925.

[16] V. Volterra, "Fluctuations in the abundance of a species considered mathematically," Nature, vol. 118, no. 2972, pp. 558-560, 1926.

[17] D. Tilman, "Competition and biodiversity in spatially structured habitats," Ecology, vol. 75, no. 1, pp. 2-16, 1994.

[18] J. A. Leon and D. B. Tumpson, "Competition between two species for two complementary or substitutable resources," Journal of Theoretical Biology, vol. 50, no. 1, pp. 185-201, 1975.

[19] S. B. Hsu, "Limiting behavior for competing species," SIAM Journal on Applied Mathematics, vol. 34, no. 4, pp. 760-763, 1978.

[20] S. B. Hsu, S. Hubbell, and P. Waltman, "A mathematical theory for single-nutrient competition in continuous cultures of micro-organisms," SIAM Journal on Applied Mathematics, vol. 32, no. 2, pp. 366-383, 1977.

[21] S. R. Hansen and S. P. Hubbell, "Single-nutrient microbial competition: qualitative agreement between experimental and theoretically forecast outcomes," Science, vol. 207, no. 4438, pp. 1491-1493, 1980.

[22] J. S. Bale, G. J. Masters, I. D. Hodkinson et al., "Herbivory in global climate change research: direct effects of rising temperature on insect herbivores," Global Change Biology, vol. 8, no. 1, pp. 1-16, 2002.

[23] M. Ladányi and L. Horváth, "A review of the potential climate change impact on insect populations," Applied Ecology and Environmental Research, vol. 8, no. 1, pp. 143-152, 2010.

[24] W. J. O’Brien, "The dynamic of nutrient limitation of phytoplankton algae: a model reconsidered," Ecology, vol. 55, no. 1, pp. 135-141, 1974.

[25] R. Levins, "Coexistence in a variable environment," The American Naturalist, vol. 114, no. 6, pp. 765-783, 1979.

[26] P. Chesson, "Multispecies competition in variable environments," Theoretical Population Biology, vol. 45, no. 3, pp. 227276, 1994.

[27] S. B. Hsu and P. Waltman, "Competition in the chemostat when one competitor produces a toxin," Japan Journal of Industrial and Applied Mathematics, vol. 15, no. 3, pp. 471-490, 1998.

[28] S. B. Hsu, Y.-S. Li, and P. Waltman, "Competition in the presence of a lethal external inhibitor," Mathematical Biosciences, vol. 167, no. 2, pp. 177-199, 2000.

[29] M. Smale, D. Byerlee, and T. Jayne, "Maize Revolution in SubSaharan Africa," The World Bank, 2001.

[30] R. Kfir, W. A. Overholt, Z. R. Khan, and A. Polaszek, "Biology and management of economically important lepidopteran cereal stem borers in Africa," Annual Review of Entomology, vol. 47, pp. 701-731, 2002.

[31] R. James and R. Washington, "Changes in African temperature and precipitation associated with degrees of global warming," Climatic Change, vol. 117, no. 4, pp. 859-872, 2013. 


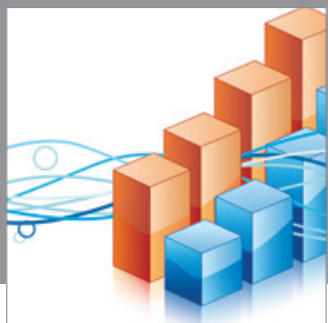

Advances in

Operations Research

mansans



The Scientific World Journal
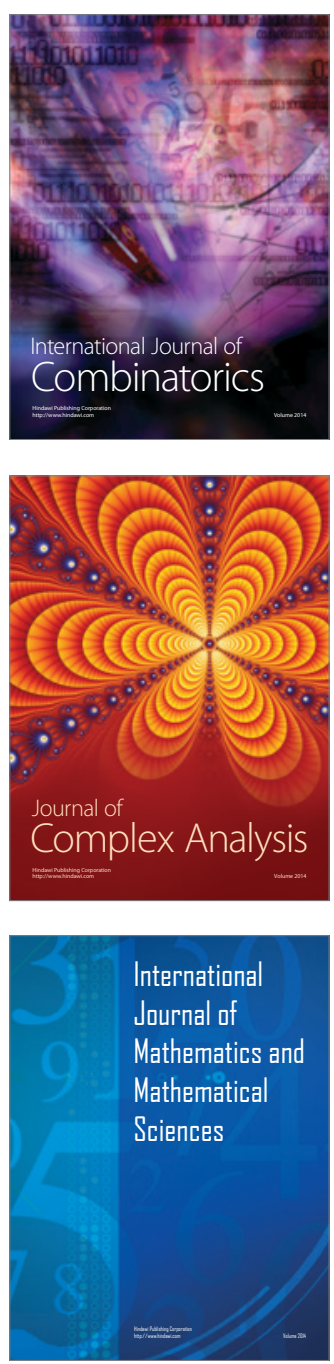
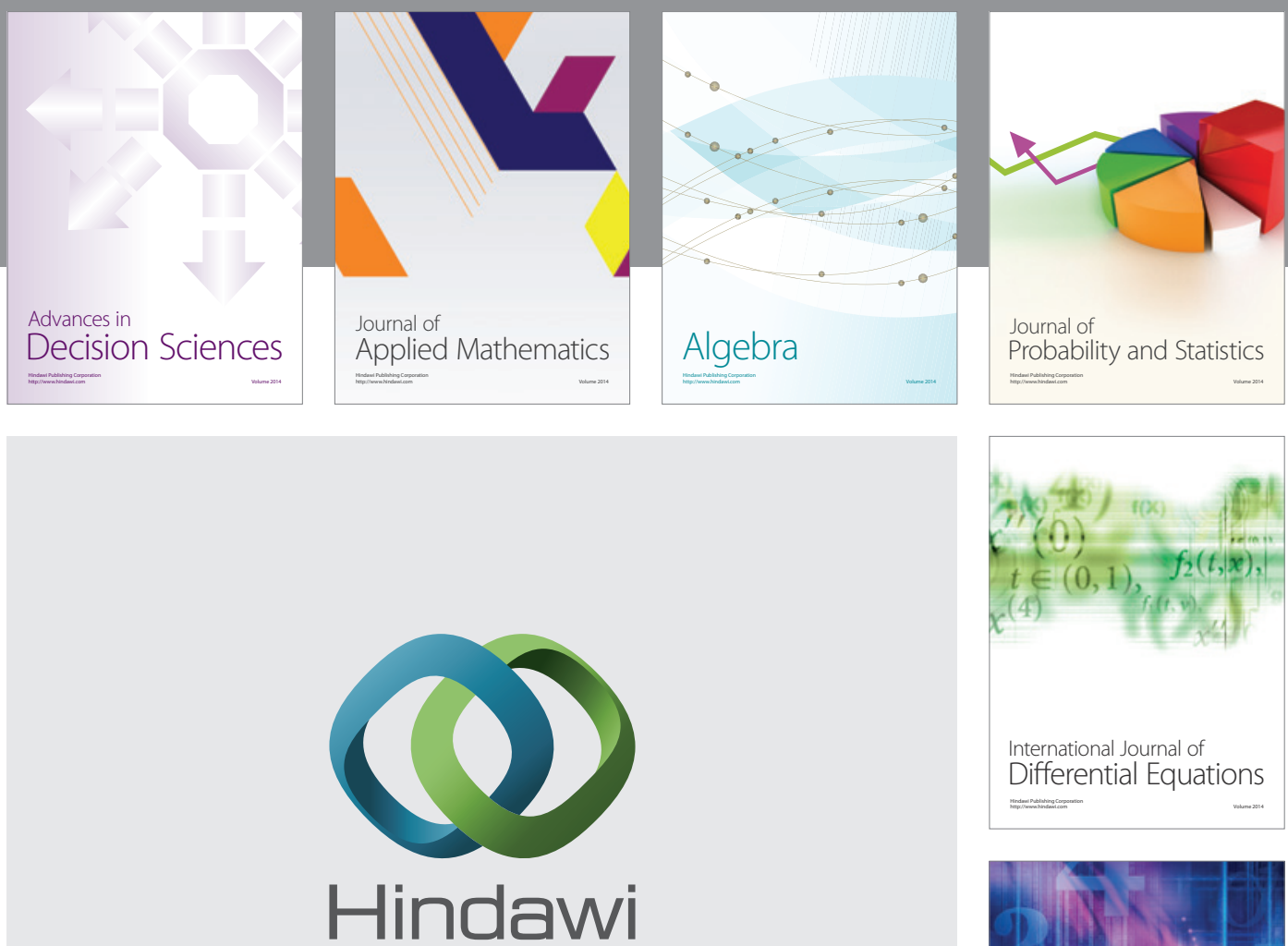

Submit your manuscripts at http://www.hindawi.com
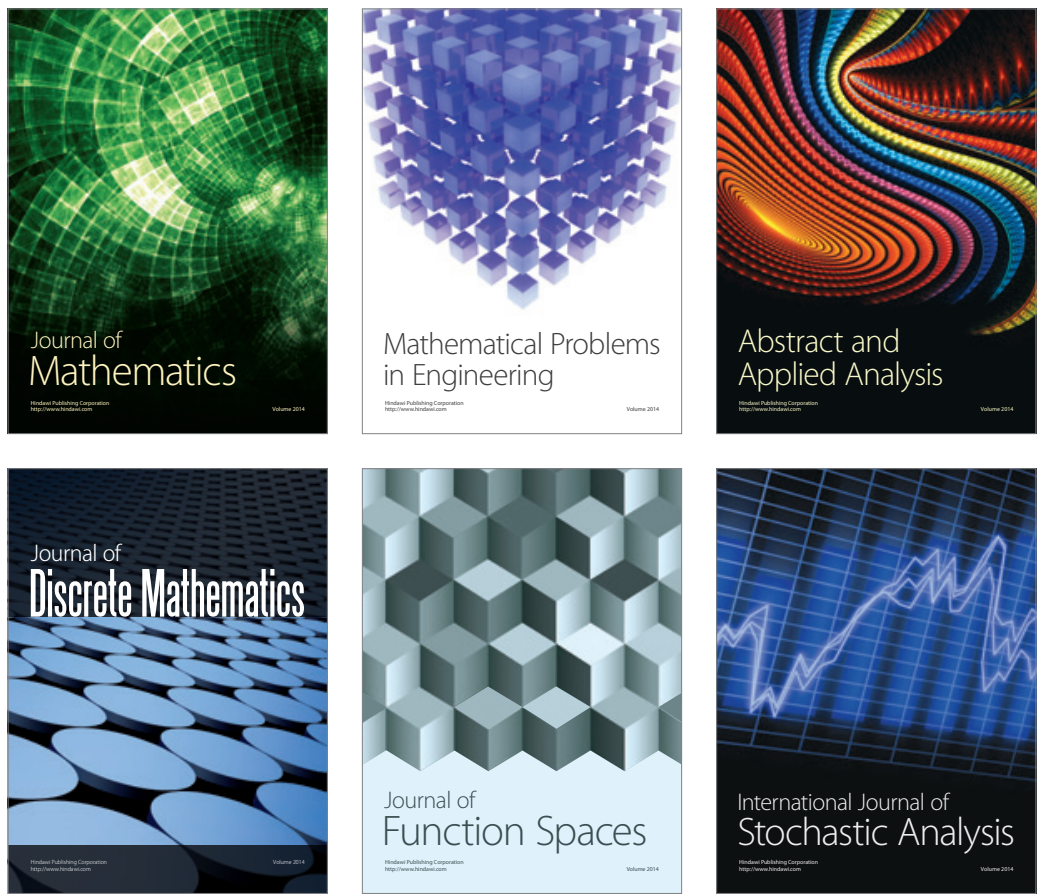

Journal of

Function Spaces

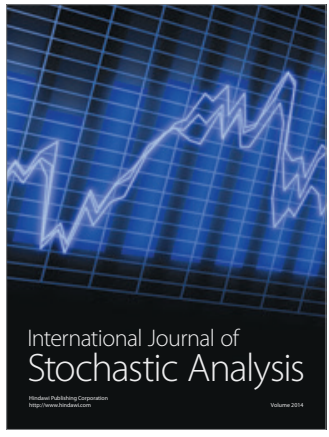


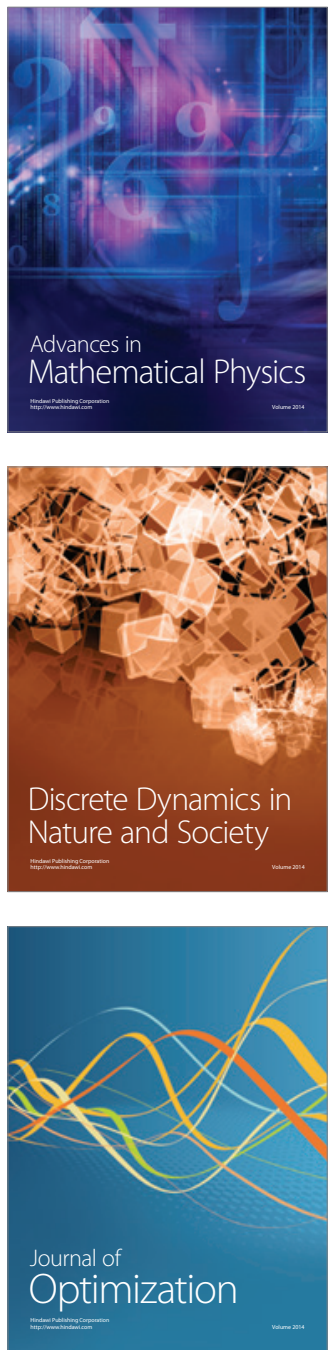